\title{
B7-H3 and B7-H4 are independent predictors of a poor prognosis in patients with pancreatic cancer
}

\author{
HONG XU $^{1 *}$, XIAOLING CHEN ${ }^{1,2 *}$, MIN TAO $^{1}, \mathrm{KAI} \mathrm{CHEN}^{1}, \mathrm{CHEN} \mathrm{CHEN}^{3}$, \\ GANG XU ${ }^{3}$, WEI LI ${ }^{1}$, SUXU YUAN ${ }^{1}$ and YIXIANG MAO ${ }^{1}$ \\ ${ }^{1}$ Department of Oncology, The First Affiliated Hospital of Soochow University, Suzhou, Jiangsu 215007; \\ ${ }^{2}$ Department of Hematology and Oncology, Central Hospital of Zhabei District, Shanghai 200070; \\ ${ }^{3}$ Department of Gastroenterology, Second Affiliated Hospital of Zhengzhou University, Zhengzhou, Henan 450014, P.R. China
}

Received February 6, 2015; Accepted December 21, 2015

DOI: $10.3892 / \mathrm{ol} .2016 .4128$

\begin{abstract}
B7-H3 and B7-H4 belong to the peripheral membrane protein $\mathrm{B} 7$ family and are hypothesized to regulate immunity. These proteins are expressed in human pancreatic cancer (PC), but their prognostic significance is poorly understood. The present study examined the association between B7-H3 and B7-H4 expression and the overall survival time in patients with $\mathrm{PC}$ that underwent surgery at the Second Affiliated Hospital to Zhengzhou University between April 2000 and January 2009. Immunohistochemical analysis demonstrated that $\mathrm{B} 7-\mathrm{H} 3$ and $\mathrm{B} 7-\mathrm{H} 4$ were expressed in 35 $(88 \%)$ and $30(75 \%)$ tumor tissue samples, respectively, which were obtained from 40 patients with PC. Statistical analysis revealed that $\mathrm{B} 7-\mathrm{H} 3$ expression was associated with an early tumor-node-metastasis stage (stage I and II; P<0.01), and B7-H4 expression was associated with tumors located in the body and tail of the pancreas $(\mathrm{P}<0.01)$ and lymph node metastasis $(\mathrm{P}=0.02)$. In addition, using Spearman's rank correlation coefficient, the present study demonstrated a positive correlation between B7-H3 expression and B7-H4 expression $(\mathrm{r}=0.37$; $\mathrm{P}=0.02)$ in tumor samples. $\mathrm{B} 7-\mathrm{H} 4$ expression $(\mathrm{P}=0.01)$, tumors located in the pancreatic body and tail $(\mathrm{P}<0.01)$, lymph node metastasis $(\mathrm{P}=0.02)$ and combined $\mathrm{B} 7-\mathrm{H} 3$ and $\mathrm{B} 7-\mathrm{H} 4$ expression $(\mathrm{P}<0.01)$ were indicators of a poor overall survival time. However, solitary B7-H4 expression $(\mathrm{P}=0.03)$ and combined $\mathrm{B} 7-\mathrm{H} 3$ and $\mathrm{B} 7-\mathrm{H} 4$ expression $(\mathrm{P}=0.04)$ remained significant prognostic factors following adjustment for other prognostic
\end{abstract}

Correspondence to: Dr Yixiang Mao or Dr Suxu Yuan, Department of Oncology, The First Affiliated Hospital of Soochow University, 188 Shizi Road, Suzhou, Jiangsu 215007, P.R. China

E-mail: maoyix@gmail.com

E-mail:szyuansuxu@sina.com

${ }^{*}$ Contributed equally

Abbreviations: PC, pancreatic cancer; OS, overall survival

Key words: B7-H3, B7-H4, pancreatic cancer, prognosis, immunohistochemistry factors in a multivariate Cox's proportional hazards regression model. Therefore, the present results indicate that solitary B7-H4 expression and a combination of B7-H3 and B7-H4 expression are independent predictors of a poor prognosis in patients with $\mathrm{PC}$.

\section{Introduction}

Pancreatic cancer (PC) is an aggressive disease and is the fourth leading cause of cancer-associated mortality in the western world, with an overall 5-year survival rate of $<6 \%$ (1). Surgical resection is the only potentially curative treatment; however, since patients are often diagnosed at advanced stages, only $15-20 \%$ of patients are candidates for a pancreatectomy (2). A prognostic evaluation is required for patients with resected pancreatic cancer (3). Such evaluations may distinguish patients with an improved prognosis from those that require additional and more vigorous treatment regimens (3).

The prognosis of patients in various types of cancer is hypothesized to be closely associated with immune evasion by tumor cells (4). Tumor cells may escape from immune surveillance through various mechanisms (5), which are dependent on the balance between co-stimulatory and co-inhibitory signals $(6,7)$. This consists of signals from the peripheral membrane protein B7 family, located on antigen presenting cells (APCs), when they interact with cluster of differentiation (CD)-28, which is located on T cells. The B7 family members (8), including B7-H3 and B7-H4, are hypothesized to play a role in tumor immune evasion, which in turn affects the prognosis of patients.

B7-H3 (9) is an accessory co-stimulatory molecule in the B7/CD28 family, although it is theorized to perform stimulatory and inhibitory functions. The stimulatory properties of B7-H3 consist of promoting $\mathrm{T}$ cell proliferation and interferon $\gamma$ production (10), while the inhibitory properties consist of impairing type $1 \mathrm{~T}$-helper cell responses and protecting cells from natural killer cell-mediated lysis (11). In certain human malignant tumors, including gastric cancer, the expression of B7-H3 has been revealed to be associated with an improved prognosis of patients (12). By contrast, in non-small cell lung cancer (13), clear-cell renal cell carcinoma (14) and 
prostate cancer (15), B7-H3 has been described as an indicator of a poor prognosis. Yamato et al (16) reported that B7-H3 was expressed in $\mathrm{PC}$, and revealed that its expression was associated with aggressive clinicopathological characteristics; however, the study did not assess the association between B7-H3 expression and the survival time of patients.

B7-H4 is a negative co-stimulatory molecule that inhibits $\mathrm{CD}^{+}{ }^{+}$and $\mathrm{CD}^{+} \mathrm{T}$ cell proliferation, cell-cycle progression and interleukin-2 production, and renders tumor cells refractory to apoptosis (17). In breast (18), non-small cell lung (12) and ovarian cancer (19), and renal cell carcinoma (20), aberrant expression of $\mathrm{B} 7-\mathrm{H} 4$ has been demonstrated to be associated with a poor clinical outcome. B7-H4, along with P53, was revealed to be a potential diagnostic marker for $\mathrm{PC}$, and the expression of B7-H4 was associated with adverse pathological features, including an increased tumor grade (21). However, the prognostic value of $\mathrm{B} 7-\mathrm{H} 4$ expression in $\mathrm{PC}$ has not been fully elucidated.

The present study evaluated the expression of B7-H3 and B7-H4 in PC and normal tissue samples using immunohistochemical analysis to determine whether B7-H3 and B7-H4 expression is an independent predictor for the overall survival (OS) time in patients with PC.

\section{Materials and methods}

Tissue samples. Pancreatic tumor samples and clinical data were obtained from 40 patients with PC (26 men and 14 women; median age at diagnosis, 54 years; range, 34-80 years), who underwent surgery without pre-operative therapy between April 2000 and January 2009 at the Second Affiliated Hospital of Zhengzhou University (Zhengzhou, Henan, China). The present study also obtained 10 normal pancreatic tissue samples, which acted as a control group and were randomly selected during the same time period from benign pancreatic tumor resections. The PC stage was classified according to the 2002 American Joint Committee on Cancer tumor-node-metastasis (TNM) staging system (22). Tumor cell differentiation was determined using the 2000 World Health Organization classification (23). Clinical data consisting of the patient age, patient gender, tumor location, histopathological type, histological grade, tumor stage and lymph node invasion was collected from medical records. The median follow-up time was 58.5 months (range, 12-134 months), and the most recent follow-up occurred on April 30, 2011. The present study was performed subsequent to obtaining informed consent from all patients and approval from the independent Institute Research Ethics Committee of The First Affiliated Hospital of Soochow University (Suzhou, China).

Immunohistochemistry. Immunostaining was performed using an EliVision ${ }^{\mathrm{TM}}$ plus kit (Maixin Biotech, Inc., Fuzhou, Fujian, China), according to the manufacturer's protocol. Formalin-fixed paraffin-embedded tissue blocks were sliced in $3-\mu \mathrm{m}$ sections and mounted on charged glass slides (Thermo Fisher Scientific, Inc., Pittsburgh, PA, USA). Antigen retrieval was performed in citrate buffer $(20 \mathrm{mmol} / \mathrm{l}$; pH 6.0; Fuzhou Maixin Biotech Co., Ltd., Fuzhou, China) at $120^{\circ} \mathrm{C}$ for $10 \mathrm{~min}$. Endogenous peroxidase activity was blocked with $3.0 \%$ hydrogen peroxide (Sinopharm Chemical Reagent Co., Ltd., Shanghai, China) for $10 \mathrm{~min}$. Mouse anti-human B7-H3 (dilution, 1:100; clone, 7D7) (24) and mouse anti-human B7-H4 (dilution, 1:100; clone, 3C8) monoclonal antibodies (gifted from Soochow University, Suzhou, China) (25) were used as the primary antibodies. Negative controls were performed using mouse monoclonal immunoglobulin G (NC-1390; Fuzhou Maixin Biotech Co., Ltd.) as the primary antibody. For visualization, the sections were incubated with 3,3'-diaminobenzidine solution (Fuzhou Maixin Biotech Co., Ltd.) and counterstained with hematoxylin (Amresco, LLC, Solon, OH, USA).

Evaluation of immunostaining. B7-H3 and B7-H4 expression was calculated as the percentage of tumor cells exhibiting immunoreactivity in the cytoplasm or on the membrane, which was determined by counting the number of B7-H3 or B7-H4-stained tumor cells out of 1,000 tumor cells in each tissue section. Using an Olympus BH2 microscope (Olympus Corporation, Tokyo, Japan), cell counts were performed at a $\mathrm{x} 400$ magnification in $\geq 5$ randomly selected fields in tumor sections. The intensity of the B7-H3 or B7-H4 expressing cells was semi-quantitatively graded as previously described (13), according to the positive cell percentage, as follows: 0 , focal expression in $<10 \%$; +, focal expression in $10-40 \%$; ++ , focal expression in $40-80 \%$; and +++ , focal expression in $>80 \%$. For the purposes of the present analysis, the samples were classified into 2 groups on the basis of staining intensity, as follows: Negative, $<10 \%$ expression; and positive, $10-100 \%$ expression.

Statistical analysis. $\chi^{2}$ and Fisher's exact tests were used to examine the association between B7-H3 and B7-H4 expression and various clinicopathological parameters, whilst Spearman's rank correlation coefficient was used to determine correlations. The overall survival times of patients with or without B7-H3 and B7-H4 expression were compared using the Kaplan-Meier method of survival time analysis and the log-rank test. For all patients, the survival time was calculated from the date of pathological diagnosis to the date of the patient succumbing to the disease or the date of the last follow-up. The data from patients that were alive at the last day of follow-up were censored. The median follow-up time was calculated using only censored data. The median survival time was also calculated. Hazard ratios (HR) and 95\% confidence intervals (CI) were estimated using univariate and multivariate Cox's proportional-hazard models. All statistical analysis was calculated with SPSS software, version 17.0 (SPSS, Inc., Chicago, IL, USA), and the P-values were two-tailed. $\mathrm{P}<0.05$ was considered to indicate a statistically significant difference.

\section{Results}

B7-H3 and B7-H4 expression in PC tissue samples. Staining for B7-H3 and B7-H4 was observed in the cell cytoplasm and membrane in cancerous and non-cancerous cells. B7-H3 expression was increased in PC tissue samples (35 out of 40 patients, 88\%; Fig. 1A) compared with normal tissue samples ( 3 out of 10 patients, $30 \%$; Fig. $1 \mathrm{C} ; \mathrm{P}<0.01$ ). Similarly, 
Table I. Association between clinicopathological parameters and B7-H3 and B7-H4 expression in pancreatic cancer tissue samples.

\begin{tabular}{|c|c|c|c|c|c|c|c|}
\hline \multirow[b]{2}{*}{ Clinicopathological parameters } & \multirow[b]{2}{*}{$\mathrm{n}$} & \multicolumn{3}{|c|}{ B7-H3 expression } & \multicolumn{3}{|c|}{ B7-H4 expression } \\
\hline & & Present, $\mathrm{n}$ & Not present, $\mathrm{n}$ & P-value & Present, $\mathrm{n}$ & Not present, $\mathrm{n}$ & P-value \\
\hline Total & 40 & 35 & 5 & & 30 & 10 & \\
\hline Age at diagnosis, years & & & & 0.63 & & & 0.47 \\
\hline$\leq 54$ years & 23 & 21 & 2 & & 16 & 7 & \\
\hline$>54$ years & 17 & 14 & 3 & & 14 & 3 & \\
\hline Gender & & & & 0.64 & & & $0.25^{*}$ \\
\hline Male & 26 & 22 & 4 & & 18 & 8 & \\
\hline Female & 14 & 13 & 1 & & 12 & 2 & \\
\hline Tumor location in pancreas & & & & 0.32 & & & $<0.01^{*}$ \\
\hline Head & 26 & 24 & 2 & & 16 & 10 & \\
\hline Body or tail & 14 & 11 & 3 & & 14 & 0 & \\
\hline Histological grade & & & & 0.33 & & & 1.00 \\
\hline Well & 10 & 10 & 0 & & 8 & 2 & \\
\hline Moderate & 14 & 11 & 3 & & 10 & 4 & \\
\hline Poor & 16 & 14 & 2 & & 12 & 4 & \\
\hline Histopathological type & & & & $0.43^{\mathrm{a}}$ & & & 0.26 \\
\hline Ductal adenocarcinoma & 36 & 31 & 5 & & 28 & 8 & \\
\hline Mucinous cystadenocarcinoma & 4 & 4 & 0 & & 2 & 2 & \\
\hline Tumor stage & & & & $<0.01$ & & & 0.10 \\
\hline $\mathrm{T} 1$ & 9 & 5 & 4 & & 8 & 1 & \\
\hline $\mathrm{T} 2$ & 11 & 11 & 0 & & 5 & 6 & \\
\hline T3 & 12 & 12 & 0 & & 10 & 2 & \\
\hline $\mathrm{T} 4$ & 8 & 7 & 1 & & 7 & 1 & \\
\hline Lymph node metastasis & & & & $0.03^{\mathrm{a}}$ & & & 0.02 \\
\hline No & 17 & 17 & 0 & & 9 & 8 & \\
\hline $\mathrm{N} 1$ & 20 & 15 & 5 & & 18 & 2 & \\
\hline TNM stage & & & & $<0.01$ & & & 0.73 \\
\hline I & 11 & 11 & 0 & & 8 & 3 & \\
\hline II & 15 & 15 & 0 & & 10 & 5 & \\
\hline III & 8 & 7 & 1 & & 7 & 1 & \\
\hline IV & 6 & 2 & 4 & & 5 & 1 & \\
\hline
\end{tabular}

${ }^{a} \chi^{2}$ test. Lymph node metastasis was not evaluated in 3 patients that underwent a palliative operation. TNM, tumor-node-metastasis.

B7-H4 expression was increased in PC tissue samples (30 out of 40 patients, 75\%; Fig. 1B) compared with normal tissue samples ( 2 out of 10 patients, 20\%; Fig. 1D; $\mathrm{P}<0.01$ ).

Association between B7-H3 and B7-H4 expression and clinicopathological parameters. The association between tumor cell B7-H3 and B7-H4 expression and clinicopathological parameters is revealed in Table I. The present study demonstrated that positive B7-H3 expression in PC tissue samples was associated with an early TNM stage $(\mathrm{P}<0.01)$. Positive B7-H4 expression was associated with tumors located in the body and tail of the pancreas, compared with tumors located in the head of the pancreas $(\mathrm{P}<0.01)$, and lymph node metastasis $(\mathrm{P}=0.02)$. The expression of either protein was not associated with the age of the patient at the time of diagnosis ( $\leq 54$ vs. $>54$ years), gender, histological grade, or histopathological type. In addition, the present study identified a positive correlation between B7-H3 expression and B7-H4 expression in PC tissue samples $(\mathrm{r}=0.37 ; \mathrm{P}=0.02)$.

Association between B7-H3 and B7-H4 expression and OS time. At the time of the final follow-up, 34 out of 40 patients had succumbed to PC; of the remaining 6 patients, 3 were alive and 3 were lost to follow-up. The patients with tumors that expressed B7-H4 had a poorer OS time compared with the patients with tumors that did not express $\mathrm{B} 7-\mathrm{H} 4(\mathrm{P}=0.01)$. Other prognostic factors were also demonstrated to decrease the OS time, including tumors located in the body and tail of the pancreas compared with tumors located in the head of the pancreas $(\mathrm{P}<0.01)$ and lymph node metastasis $(\mathrm{P}=0.02)$. The 
Table II. Multivariate backward stepwise Cox's proportional hazards analyses demonstrating clinicopathological parameters that were associated with a poorer overall survival time in patients with pancreatic cancer.

\begin{tabular}{lccr}
\hline Clinicopathological parameter & HR & $95 \%$ CI & P-value \\
\hline B7-H3 and B7-H4 expression & 0.17 & $0.03-0.94$ & 0.04 \\
B7-H4 expression & 0.15 & $0.03-0.80$ & 0.03 \\
Lymph node metastasis & 1.77 & $0.15-20.77$ & 0.65 \\
Tumor located in body or tail of pancreas & 0.73 & $0.17-3.20$ & 0.68 \\
\hline
\end{tabular}

HR, hazard ratio; CI, confidence interval.

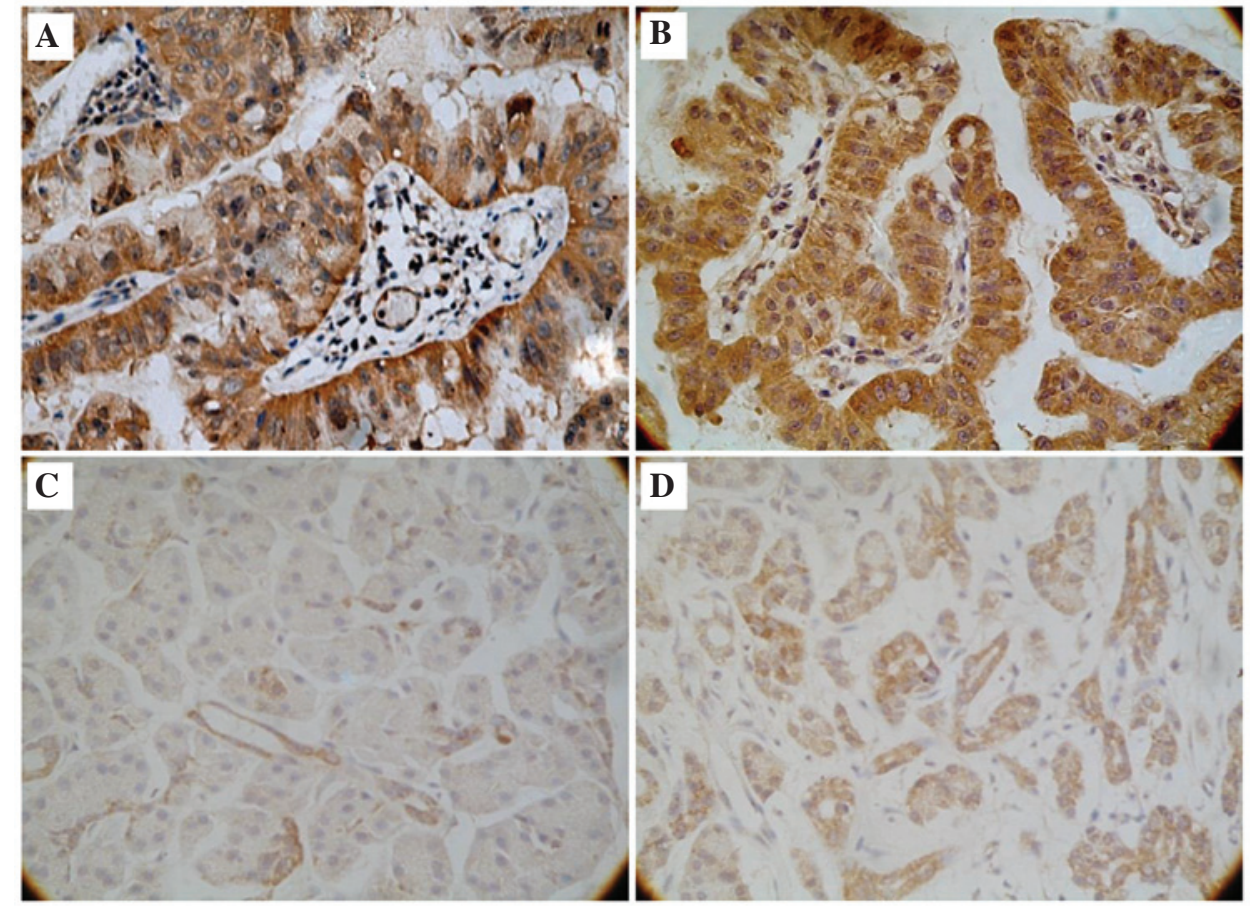

Figure 1. Immunohistochemical staining demonstrating the expression of B7-H3 and B7-H4 in PC and normal pancreatic tissues. (A) Cytoplasmic expression of B7-H3 in PC tissue (magnification, x400). (B) Cytoplasmic expression of B7-H4 in PC tissue (magnification, $\mathrm{x} 400$ ). (C) High expression of B7-H3 in the acini of normal pancreatic tissue (magnification, x100). (D) Low expression of B7-H4 in the intercalated cells of normal pancreatic tissue (magnification, x100). PC, pancreatic cancer.

patients with tumors that did not express B7-H3 and B7-H4 had an improved prognosis compared with the patients with tumors that did express 1 or 2 of the proteins $(\mathrm{P}<0.01)$.

Following adjustments for tumor location and lymph node metastasis, the patients with tumors that expressed the 2 proteins $\mathrm{B} 7-\mathrm{H} 3$ and $\mathrm{B} 7-\mathrm{H} 4$ were at an increased risk of mortality compared with the patients with tumors that expressed only 1 protein or did not express either proteins (HR, 0.17; 95\% CI, 0.03-0.94; P=0.04; Table II). In addition, patients with tumors that expressed B7-H4 were at an increased risk of mortality compared with the patients with tumors that did not express B7-H4 (HR, 0.15; 95\% CI, 0.03-0.80; $\mathrm{P}=0.03$; Table II).

\section{Discussion}

B7-H3 and B7-H4 are two novel members of the B7 superfamily of peripheral membrane proteins that are expressed on APCs and have been implicated in tumor immunogenicity and cancer development $(13,26,27)$. The present study demonstrated that B7-H3 and B7-H4 were expressed in the cytoplasm and membrane of cancerous and non-cancerous pancreatic cells, and that B7-H4 expression or the combination of B7-H3 and B7-H4 expression in cancerous cells was associated with a decreased overall survival time, independent of other prognostic factors that are also associated with B7-H3 and B7-H4 expression. Although other studies have demonstrated an association between B7-H3 or B7-H4 expression and clinicopathological parameters, in particular that increased B7-H1 expression in PC tissues is associated with a decreased overall survival time (28), the present study identified that an expression of B7-H4 and a simultaneous combined expression of $\mathrm{B} 7-\mathrm{H} 3$ and $\mathrm{B} 7-\mathrm{H} 4$ are independent predictors of a poor prognosis in patients with $\mathrm{PC}$.

Previous evidence (29) indicates that B7 family molecules are expressed in PC and that their interactions with 
corresponding receptors are directly associated with the $\mathrm{T}$ cell engagement of an antigen. An upregulation of B7-H3 and B7-H4 expression in tumor tissue was detected in non-small cell lung (13) and prostate cancer (15) in previous studies; however, only a few studies have evaluated B7-H3 or B7-H4 expression levels in PC (30). Yamato et al (16) identified that B7-H3 expression in PC was associated with an advanced tumor stage and lymph node metastasis, and Awadallah et al (21) reported that B7-H4 was expressed on cytological specimens, which were obtained by endoscopic ultrasound-guided fine needle aspiration and surgical specimens from patients with PC. The overall expression of B7-H4 in benign tissues was relatively decreased compared with that observed in the majority of carcinoma patients. In the survival and correlation analyses of 24 patients (17 surgically resected cases and 7 biopsy cases) that succumbed to pancreatic adenocarcinoma, there was no statistically significant association identified between patient survival rate and the proportion of cells that stained positively for $\mathrm{B} 7-\mathrm{H} 4$ expression $(\mathrm{P}=0.55)$ or the intensity of $\mathrm{B} 7-\mathrm{H} 4$ staining $(\mathrm{P}=0.26)(21)$. The present study demonstrated that B7-H3 and B7-H4 expression were associated with certain clinicopathological features of patients with PC, including the increased expression of B7-H3 in an early TNM stage (stage I or II; $\mathrm{P}<0.01$ ), the increased expression of $\mathrm{B} 7-\mathrm{H} 4$ associated with tumors located in the body and tail of the pancreas compared to those located in the head of the pancreas $(\mathrm{P}<0.01)$ and lymph node metastasis $(\mathrm{P}=0.02)$.

The prognostic role of $\mathrm{B} 7-\mathrm{H} 3$ in cancer is unclear. In gastric cancer (12), an increased B7-H3 expression is revealed to be associated with an improved prognosis compared with a decreased B7-H3 expression; however, in non-small cell lung cancer (13), renal cell carcinoma (14), and prostate cancer (15), B7-H3 served as a marker of poor prognosis or disease metastasis. In the present study, B7-H3 was more likely to be expressed in PC tissue compared with normal pancreatic tissue, which is consistent with a previous study (16). Although the present findings did not demonstrate any survival benefit from the presence of B7-H3 expression, it was observed that B7-H3 expression was increased in late-stage tumors (T2-T4) compared to early-stage tumors (T1) and in tumors that had not metastasized to the lymph nodes compared with tumors that had metastasized $(\mathrm{P}<0.01$ and $\mathrm{P}=0.03$, respectively). These results suggest that B7-H3 may be involved in the development of human PC. However, it is unclear why B7-H3 expression was not a predictor of OS time, considering its positive correlation with B7-H4 expression as well as the decreased OS time observed in patients with tumors that were positive for a combination of B7-H3 and B7-H4 expression. The inconsistent association between $\mathrm{B} 7-\mathrm{H} 3$ expression and prognosis in $\mathrm{PC}$ and other cancers may be partly explained by an unknown receptor for B7-H3 $(27,31)$ and the complex tumor microenvironment (32).

The present study revealed that the presence of solitary B7-H4 expression or a combination of B7-H3 and B7-H4 expression in human PC may serve as independent predictors of poor prognosis. Mugler et al (33) and Simon et al (34) hypothesized that B7-H4 may induce immune evasion through the suppression of $\mathrm{T}$ cell activation and cytokine secretion and the development of cytotoxicity. In vitro and in vivo studies (35) have suggested that $\mathrm{B} 7-\mathrm{H} 4$ overexpression in numerous tumor types may allow tumors to avoid eliciting an antitumor immune response. Although the present results suggest that solitary B7-H4 expression and a combination of B7-H3 and B7-H4 expression may be prognostic factors for $\mathrm{PC}$, the exact mechanisms by which expression of these proteins leads to a decreased survival time remains to be clarified.

A limitation of the present study was the relatively small sample size, which may lead to an overestimation of the magnitude of the association between variables. Considering the potential prognostic value of B7-H3 and B7-H4 in patients with $\mathrm{PC}$, which would aid in the clarification of the most effective treatments to administer to patients, additional retrospective studies of a larger scale are required to confirm the association that the present study observed between the expression of B7-H3 and B7-H4 and the clinical outcomes in PC patients.

In conclusion, the present findings indicate that B7-H3 and B7-H4 are more likely to be expressed in PC tissue compared with normal pancreatic tissue, and that solitary B7-H4 expression and a combination of B7-H3 and B7-H4 expression are associated with a decreased OS time in patients with PC. Therefore, solitary B7-H4 and a combined B7-H3 and B7-H4 expression in PC tissues may be useful independent predictors of prognosis. Large-scale studies are required to validate these findings.

\section{Acknowledgements}

The authors would like to thank Dr Lingchuan Guo (The First Affiliated Hospital of Soochow University, Suzhou, China) for providing technical assistance and Ms. Erica Goodoff (The University of Texas MD Anderson Cancer Center, Houston, USA) for editing the manuscript. The present study was supported by the National Natural Science Foundation of China (grant nos. 30901765, 81272542 and 81101867), Medical Scientific Research Project of Jiangsu Provincial Bureau of Health (grant no. Z201206), China International Medical Foundation (grant no. CIMF-F-H001-057), Special Foundation of Wu Jieping Medical Foundation for Clinical Scientific Research (grant no. 320.6753.1225), Science and Education for Health Foundation of Suzhou for Youth (grant no. SWKQ1003) and Science and Technology Project Foundation of Suzhou (grant no. SYS201112).

\section{References}

1. Siegel R, Naishadham D and Jemal A: Cancer statistics, 2012. CA Cancer J Clin 62: 10-29, 2012.

2. Katz MH, Pisters PW, Evans DB, Sun CC, Lee JE, Fleming JB, Vauthey JN, Abdalla EK, Crane CH, Wolff RA, et al: Borderline resectable pancreatic cancer: The importance of this emerging stage of disease. J Am Coll Surg 206: 833-846, 2008.

3. Geer RJ and Brennan MF: Prognostic indicators for survival after resection of pancreatic adenocarcinoma. Am J Surg 165: 68-72, 1993.

4. Nagaraj S, Gupta K, Pisarev V, Kinarsky L, Sherman S, Kang L, Herber DL, Schneck J and Gabrilovich DI: Altered recognition of antigen is a mechanism of CD8+ T cell tolerance in cancer. Nat Med 13: 828-835, 2007.

5. Zou W: Immunosuppressive networks in the tumour environment and their therapeutic relevance. Nat Rev Cancer 5: 263-274, 2005 
6. Greenwald RJ, Freeman GJ and Sharpe AH: The B7 family revisited. Annu Rev Immunol 23: 515-548, 2005.

7. Subudhi SK, Alegre ML and Fu YX: The balance of immune responses: Costimulation verse coinhibition. J Mol Med Berl 83: 193-202, 2005.

8. Driessens G, Kline J and Gajewski TF: Costimulatory and coinhibitory receptors in anti-tumor immunity. Immunol Rev 229: 126-144, 2009.

9. Chapoval AI, Ni J, Lau JS, Wilcox RA, Flies DB, Liu D, Dong H, Sica GL, Zhu G, Tamada K and Chen L: B7-H3: A costimulatory molecule for $\mathrm{T}$ cell activation and IFN-gamma production. Nat Immunol 2: 269-274, 2001.

10. Prasad DV, Nguyen T, Li Z, Yang Y, Duong J, Wang Y and Dong C: Murine B7-H3 is a negative regulator of T cells. J Immunol 173: 2500-2506, 2004.

11. Suh WK, Gajewska BU, Okada H, Gronski MA, Bertram EM, Dawicki W, Duncan GS, Bukczynski J, Plyte S, Elia A, et al: The B7 family member B7-H3 preferentially down-regulates Thelper type 1-mediated immune responses. Nat Immunol 4: 899-906, 2003.

12. Wu CP, Jiang JT, Tan M, Zhu YB, Ji M, Xu KF, Zhao JM, Zhang GB and Zhang XG: Relationship between co-stimulatory molecule B7-H3 expression and gastric carcinoma histology and prognosis. World J Gastroenterol 12: 457-459, 2006.

13. Sun Y, Wang Y, Zhao J, Gu M, Giscombe R, Lefvert AK and Wang X: B7-H3 and B7-H4 expression in non-small-cell lung cancer. Lung Cancer 53: 143-151, 2006.

14. Crispen PL, Sheinin Y, Roth TJ, Lohse CM, Kuntz SM, Frigola X, Thompson RH, Boorjian SA, Dong H, Leibovich BC, et al: Tumor cell and tumor vasculature expression of B7-H3 predict survival in clear cell renal cell carcinoma. Clin Cancer Res 14: 5150-5157, 2008.

15. Zang X, Thompson RH, Al-Ahmadie HA, Serio AM, Reuter VE, Eastham JA, Scardino PT, Sharma P and Allison JP: B7-H3 and B7x are highly expressed in human prostate cancer and associated with disease spread and poor outcome. Proc Natl Acad Sci USA 104: 19458-19463, 2007.

16. Yamato I, Sho M, Nomi T, Akahori T, Shimada K, Hotta K, Kanehiro H, Konishi N, Yagita H and Nakajima Y: Clinical importance of B7-H3 expression in human pancreatic cancer. $\mathrm{Br}$ J Cancer 101: 1709-1716, 2009.

17. Prasad DV, Richards S, Mai XM and Dong C: B7S1, a novel B7 family member that negatively regulates $\mathrm{T}$ cell activation. Immunity 18: 863-873, 2003

18. Tringler B, Zhuo S, Pilkington G, Torkko KC, Singh M, Lucia MS, Heinz DE, Papkoff J and Shroyer KR: B7-H4 is highly expressed in ductal and lobular breast cancer. Clin Cancer Res 11: 1842-1848, 2005.

19. Tringler B, Liu W, Corral L, Torkko KC, Enomoto T, Davidson S, Lucia MS, Heinz DE, Papkoff J and Shroyer KR: B7-H4 overexpression in ovarian tumors. Gynecol Oncol 100: 44-52, 2006.

20. Krambeck AE, Thompson RH, Dong H, Lohse CM, Park ES Kuntz SM, Leibovich BC, Blute ML, Cheville JC and Kwon ED: B7-H4 expression in renal cell carcinoma and tumor vasculature: Associations with cancer progression and survival. Proc Natl Acad Sci USA 103: 10391-10396, 2006.

21. Awadallah NS, Shroyer KR, Langer DA, Torkko KC, Chen YK, Bentz JS, Papkoff J, Liu W, Nash SR and Shah RJ: Detection of B7-H4 and p53 in pancreatic cancer: Potential role as a cytological diagnostic adjunct. Pancreas 36: 200-206, 2008.
22. Greene FL, Page DL, Fleming ID, Fritz AG, Balch CM, Haller DG and Morrow M (eds): Exocrine pancreas. In: AJCC Cancer Staging Manual. 6th edition. Springer, New York, NY, pp157-164, 2002

23. Klöppel G, Hruban RH, Longneck DS, Adler G, Kern SE and Partanen TJ: Tumours of the exocrine pancreas. In: World Health Organization Classification of Tumours. Pathology and Genetics of Tumours of the Digestive System. Hamilton SR and Aaltonen LA (eds). Vol 2. IARC Press, Lyon, pp219-252, 2000.

24. Zhou YH, Chen YJ, Ma ZY, Xu L, Wang Q, Zhang GB, Xie F, Ge Y, Wang XF and Zhang XG: 4IgB7-H3 is the major isoform expressed on immunocytes as well as malignant cells. Tissue Antigens 70: 96-104, 2007.

25. Chen LJ, Sun J, Wu HY, Zhou SM, Tan Y, Tan M, Shan BE, Lu BF and Zhang XG: B7-H4 expression associates with cancer progression and predicts patient's survival in human esophageal squamous cell carcinoma. Cancer Immunol Immunother 60: 1047-1055, 2011.

26. Fauci JM, Straughn JM Jr, Ferrone S and Buchsbaum DJ: A review of $\mathrm{B} 7-\mathrm{H} 3$ and $\mathrm{B} 7-\mathrm{H} 4$ immune molecules and their role in ovarian cancer. Gynecol Oncol 127: 420-425, 2012.

27. Yi KH and Chen L: Fine tuning the immune response through B7-H3 and B7-H4. Immunol Rev 229: 145-151, 2009.

28. Chen XL, Yuan SX, Chen C, Mao YX, Xu G and Wang XY: Expression of B7-H1 protein in human pancreatic carcinoma tissues and its clinical significance. Ai Zheng 28: 1328-1332, 2009 (In Chinese).

29. Nomi T, Sho M, Akahori T, Hamada K, Kubo A, Kanehiro H, Nakamura S, Enomoto K, Yagita $H$, Azuma $M$ and Nakajima Y: Clinical significance and therapeutic potential of the programmed death-1 ligand/programmed death-1 pathway in human pancreatic cancer. Clin Cancer Res 13: 2151-2157, 2007.

30. Qian Y, Hong B, Shen L, Wu Z, Yao H and Zhang L: B7-H4 enhances oncogenicity and inhibits apoptosis in pancreatic cancer cells. Cell Tissue Res 353: 139-151, 2013.

31. Roth TJ, Sheinin Y, Lohse CM, Kuntz SM, Frigola X, Inman BA, Krambeck AE, McKenney ME, Karnes RJ, Blute ML, et al: B7-H3 ligand expression by prostate cancer: A novel marker of prognosis and potential target for therapy. Cancer Res 67: 7893-7900, 2007.

32. Kuang DM, Zhao Q, Peng C, Xu J, Zhang JP, Wu C and Zheng L: Activated monocytes in peritumoral stroma of hepatocellular carcinoma foster immune privilege and disease progression through PD-L1. J Exp Med 206: 1327-1337, 2009.

33. Mugler KC, Singh M, Tringler B, Torkko KC, Liu W, Papkoff J and Shroyer KR: B7-H4 expression in a range of breast pathology: Correlation with tumor T cell infiltration. Appl Immunohistochem Mol Morphol 15: 363-370, 2007.

34. Simon I, Katsaros D, Rigault de la Longrais I, Massobrio M, Scorilas A, Kim NW, Sarno MJ, Wolfert RL and Diamandis EP: B7-H4 is over-expressed in early-stage ovarian cancer and is independent of CA125 expression. Gynecol Oncol 106: 334-341, 2007.

35. Choi IH, Zhu G, Sica GL, Strome SE, Cheville JC, Lau JS, Zhu Y, Flies DB, Tamada $\mathrm{K}$ and Chen L: Genomic organization and expression analysis of $\mathrm{B} 7-\mathrm{H} 4$, an immune inhibitory molecule of the B7 family. J Immunol 171: 4650-4654, 2003. 